\title{
A splicing enhancer in the human fibronectin alternate ED1 exon interacts with SR proteins and stimulates U2 snRNP binding
}

\author{
Alain Lavigueur, Hélène La Branche, Alberto R. Kornblihtt ${ }^{1}$ and Benoit Chabot $^{2}$ \\ Département de Microbiologie, Faculté de Médecine, Université de Sherbrooke, Sherbrooke, Québec, J1H 5N4 Canada; \\ ${ }^{1}$ Instituto de Investigaciones en Ingeniería Genética y Biología Molecular (INGEBI-CONICET), Vuelta de Obligado 2490, \\ 1428 Buenos Aires, Argentina
}

The inclusion of the 270-nucleotide human fibronectin ED1 exon in HeLa cells requires the presence of a centrally located 81-nucleotide exon sequence. We have conducted a series of in vitro experiments aimed at understanding the structural and functional features associated with this splicing enhancer (SE). Using hybrid model pre-mRNA substrates, we show that the SE element markedly stimulates the use of the 3' splice site of ED1. Deletion and replacement analysis identifies the stimulating sequences as a purine-rich stretch of 9 nucleotides (GAAGAAGAC). The SE element stimulates splicing to the ED1 3' splice site from various positions within the exon except when placed beyond 293 nucleotides downstream from that $3^{\prime}$ splice site. The action of the enhancer is not limited to the ED1 acceptor site because the SE element stimulates human $\beta$-globin splicing and also induces the use of a 3 ' splice site in a prokaryotic sequence in vitro. We have explored the mechanism of action of the fibronectin splicing enhancer and found that the SE element is required for efficient assembly of early splicing complexes, allowing a more efficient interaction of the U2 snRNP with branch site sequences. In competition experiments, an RNA containing mainly SE sequences specifically abolished the action of the SE element, suggesting that factors bind the enhancer element to mediate stimulation of splicing. Using RNA mobility shift assays we show that SR proteins interact specifically with the SE element. Our results demonstrate that exon sequences lying in the SE element play a crucial role in specifying splice site recognition through interactions with factors binding to the 3 ' splice site.

[Key Words: Fibronectin; splice site selection; splicing; SR proteins; snRNPs]

Received June 1, 1993; revised version accepted September 13, 1993.

Alternative splicing of mRNA precursors plays a fundamental role in the regulation of eukaryotic gene expression, but the mechanisms that underlie these regulatory events are just beginning to be deciphered (Smith et al. 1989; Maniatis 1991). In contrast to the mechanisms regulating splice site selection, the role of the factors involved in the generic splicing reaction is better understood (Green 1991; Guthrie 1991). Splicing takes place on a large multicomponent complex called the spliceosome, which includes a set of the four small nuclear ribonucleoproteins (snRNPs) U1, U2, U4/U6, and U5. Multiple snRNP/snRNP and snRNP/pre-mRNA interactions are crucial in specifying the efficiency and the precision of splicing [recent examples can be found in Newman and Norman (1991,1992); Madhani and Guthrie (1992); Reich et al. (1992); Sawa and Abelson (1992): Wassarman and Steitz (1992)]. In addition to snRNPs,

\footnotetext{
${ }^{2}$ Corresponding author.
}

several proteins interacting with various parts of the premRNAs have now been identified. In particular, the polypyrimidine stretch located between the branch site and the dinucleotide AG at the $3^{\prime}$ splice junction is a binding site for several nuclear proteins including $\mathrm{U} 2 \mathrm{AF}^{65}$, the presence of which is required for U2 snRNP binding to the branch site (Ruskin et al. 1988; Zamore and Green 1989). Other factors capable of interacting with 3' splice site sequences include the heterogeneous nuclear ribonucleoparticle ( $\mathrm{hnRNP}$ ) proteins $\mathrm{Al}, \mathrm{C}, \mathrm{D}$, and I/PTB (Swanson and Dreyfuss 1988; Garcia-Blanco et al. 1989).

The selection of splice sites in constitutively or alternatively spliced pre-mRNAs is determined by several parameters, including the proximity and strength of splicing signals (Green 1991). In some cases, the formation of RNA secondary structures participates in the regulation of splice site selection (Clouet et al. 1991; Domenjoud et al. 1991|. Intron sequences other than those specifying splicing signals can also influence regulated splice site 
selection. In the case of $n$-src, a coupling between splice site interference and the action of a specific intron element appears important for tissue-specific regulation of splicing in vivo and in vitro (Black 1991,1992). Several studies testify to the importance of exon sequences in splice site selection. Some exon sequences repress the use of adjacent splice sites (Gallego et al. 1992; Nemeroff et al. 1992; Siebel et al. 1992) while other exon elements act positively by stimulating splicing (Reed and Maniatis 1986; Hampson et al. 1989; Streuli and Saito 1989; Libri et al. 1990; Cooper 1992; Cote et al. 1992; Graham et al. 1992). Recently, purine-rich elements acting as splicing enhancers have been identified in two mammalian alternate exons (Watakabe et al. 1993; Xu et al. 1993). In Drosophila, six copies of a 13-nucleotide repeat promote the interaction of the RNA-binding proteins Tra and Tra2 , which in turn improve the utilization of the upstream 3 ' splice site of the female-specific doublesex exon (Hedley and Maniatis 1991; Hoshijima et al. 1991; Tian and Maniatis 1992). In most cases, however, the nature of the exon sequences, the identity of trans-acting factors, and the mechanism involved in the stimulation remain unknown.

We have chosen the ED1 region of the fibronectin gene to investigate the role of exon sequences in splice site selection. Plasma and cellular fibronectins are produced via differential inclusion of the ED1 and ED2 exons (also known as exons EDIIIA and EDIIIB, respectively). These alternate exons are found in cellular but not plasma fibronectin, suggesting a direct role for the encoded protein regions in cellular adhesion processes. The 270-nucleotide EDl exon contains a centrally located 81-nucleotide region that is essential for exon EDl inclusion in HeLa cells (Mardon et al. 1987). We report that a 9-nucleotide purine-rich sequence located within this splicing enhancer (SE) element stimulates EDl $3^{\prime}$ splice site utilization in vitro. We have investigated the positional characteristics of the SE element, and we show that SR proteins specifically bind to the SE element. Because the SR proteins constitute a family of splicing factors involved in splice site selection (Fu et al. 1992; Mayeda et al. 1992; Zahler et al. 1993a,b), our findings suggest that the interaction between SR proteins and the SE element is a key feature involved in the regulated splicing of the EDl alternate exon.

\section{Results}

The fibronectin SE element stimulates the use of the ED1 acceptor site in vitro

To address the contribution of the SE element to ED1 3' splice site utilization, we first used the hybrid AF6 RNA which contains the adenovirus L1 exon, a hybrid intron of 408 nucleotides, and the first 180 nucleotides of the ED1 exon containing the complete SE element (Fig. 1A). Splicing of AF6 RNA was readily detected in vitro (Fig. $1 B$, lanes 3,4 ), whereas the absence of the SE element in AF1 RNA considerably reduced L1/ED1 splicing (Fig. 1B, lanes 1,2$)$. The SE element stimulated splicing by an average of 10-fold (see also Figs. 2B and 4B). Juxtaposition of

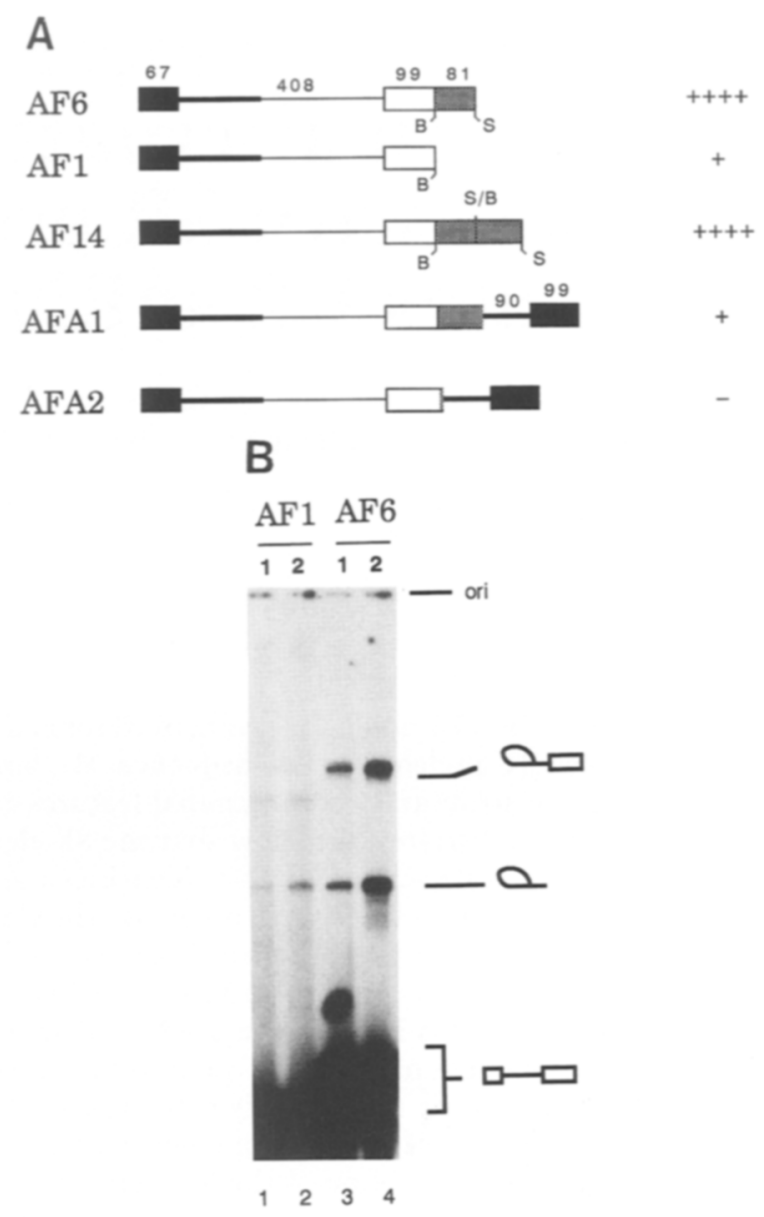

Figure 1. In vitro splicing to the ED1 $3^{\prime}$ splice site using premRNAs with and without the SE element. $(A)$ Diagrammatic representation of the pre-mRNAs tested for splicing in vitro. (Open boxes) Exon sequences; (horizontal lines) introns. The fibronectin EDl exon is divided into three parts to illustrate the position of the SE element (stippled boxes) and flanking exon sequences. (Black boxes) Adenovirus exon sequences; (thick lines) intron sequences. The size, in nucleotides, of the various parts of the pre-mRNA is shown. The positions of the BstEII (B) and StuI $(\mathrm{S})$ sites on the corresponding DNA template are shown. The first 225 nucleotides of each transcript are derived from the adenovirus $\mathrm{Ll}$ exon and part of the first intron, whereas the terminal part of AFA1 and AFA2 RNAs is derived from the adenovirus L2 exon and adjacent sequences. The relative efficiency of $\mathrm{Ll} / \mathrm{EDl}$ splicing is indicated for each premRNA and is based on the production of lariat intron. $(B)$ In vitro splicing of simple substrates lacking (AFl, lanes 1,2) or containing (AF6, lanes 3,4) the SE element. Pre-mRNAs were incubated for the time (in hr, top). The separation of the splicing products and intermediates was performed on a $5 \%$ denaturing acrylamide gel. Only the top part of the gel is shown here and in later figures to depict the lariat intermediates and lariat products that migrate above the pre-mRNAs. Free $5^{\prime}$ exon and mRNAs were detected (not shown, but see Fig. 5B), but estimation of splicing efficiencies using these molecules was difficult because of pre-mRNA degradation.

another SE element to generate a head-to-tail tandem repeat (AF14 RNA) did not stimulate splicing further 
(data not shown). The SE element also stimulated L1/ ED1 splicing when a strong competing $3^{\prime}$ splice site was positioned downstream (AFAl RNA, Fig. 1A; data not shown). We conclude that the fibronectin SE element stimulates $3^{\prime}$ splice site recognition of the fibronectin ED1 exon in vitro.

We then attempted to address the role of the SE element in $5^{\prime}$ splice site utilization in vitro by pairing the complete ED1 exon with the downstream constitutive exon +1 . We could not detect splicing of this RNA in a HeLa extract, possibly because the combination involved two weak splicing signals (data not shown). In contrast, pairing the ED1 donor site with the adenovirus (L2) 3' splice site restored in vitro splicing, and removal of the SE element did not affect splicing (data not shown). Although this result indicates that the SE element does not stimulate ED1/L2 splicing in vitro, it is possible that the SE element stimulates the ED1 donor site in vivo when paired with the $3^{\prime}$ splice site of exon +1 .

\section{A 9-nucleotide purine-rich sequence in the $S E$} element is responsible for stimulation

To further define the sequences of the SE element in- volved in enhancing ED1 $3^{\prime}$ splice site utilization, we used RNA substrates ending at different positions within the SE element (Fig. 2A). These RNAs were generated either by linearization of DNA templates at convenient restriction sites or by oligonucleotide-targeted RNase $\mathrm{H}$ degradation of a longer pre-mRNA. AF6 and AF5 RNAs, which contain 81 and 73 nucleotides of the SE element, respectively, were spliced with comparable efficiencies (Fig. 2B, lanes 3,5). AF4 RNA, which leaves 69 nucleotides of the SE element, was spliced with an efficiency similar to AF6 (Fig. 2B, lane 4). In contrast, AF3 and AF2 RNAs, which contained 38 and 21 nucleotides of the SE element, respectively, were always spliced with the low efficiency typical of AF1 RNA (Fig. 2B, lanes 1,2,8,9). These results show that the 31-nucleotide region between the oligonucleotide-directed cut and the PstI site contains sequences essential for the stimulation of L1/ ED1 splicing (Fig. 3). This conclusion is supported by the analysis of AF5 1 l RNA, which contained the last 52 nucleotides of the SE element and is spliced as efficiently as AF6 RNA (Fig. 2B, lane 7).

The splicing of AF7 and AF8 RNAs indicated that no other regions of the ED1 region downstream of the SE element could affect L1/EDl splicing in vitro (Fig. 2B,

\section{A}

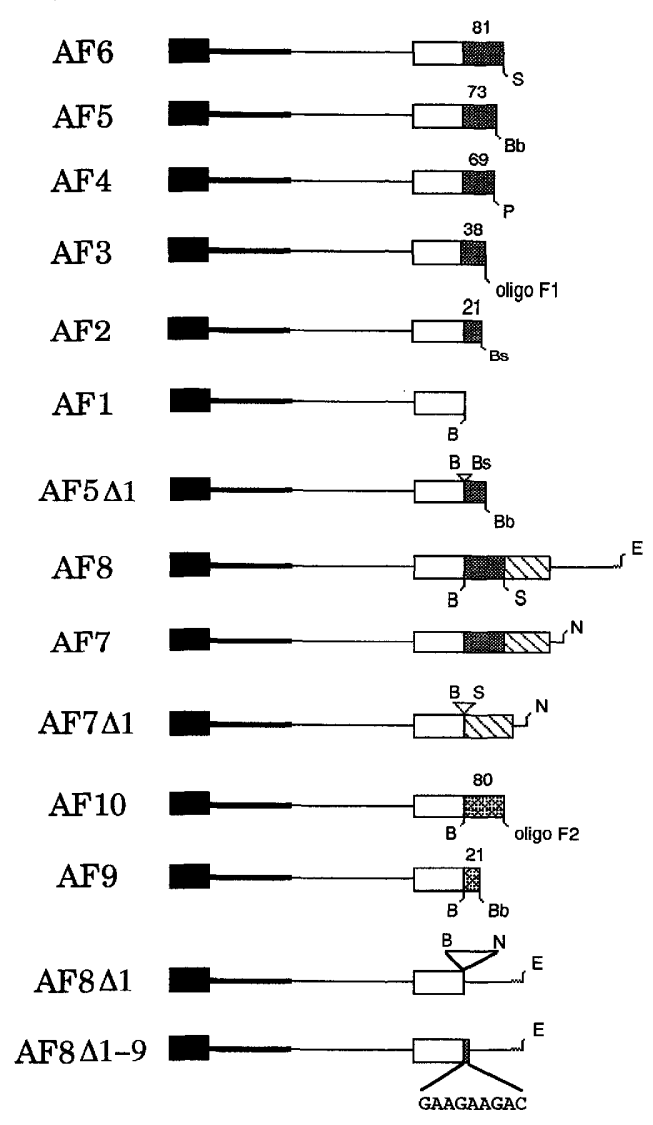

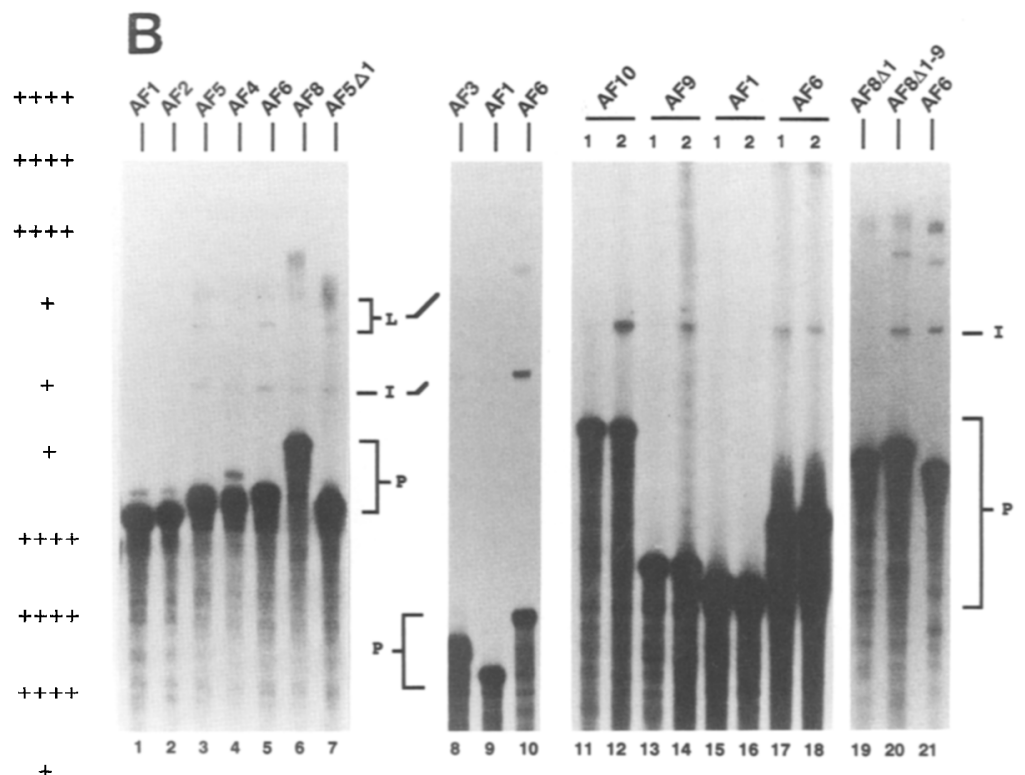

Figure 2. In vitro splicing of pre-mRNAs containing deletions and substitutions in the SE element. $(A)$ Schematic representation of the precursors used in in vitro splicing. (Serrate lines in AF8, AF8 81 , and AF8 $\Delta 1-9$ ) Plasmid sequences. The positions of BstEII (B), StuI (S), BbsI $(\mathrm{Bb}), \operatorname{Pst}(\mathrm{P}), B s u 36 \mathrm{I}(\mathrm{Bs}), N c o \mathrm{I}(\mathrm{N}), B s m \mathrm{I}(\mathrm{Bm})$, and $E c o \mathrm{RI}(\mathrm{E})$ sites used to generate runoff transcripts and internal deletions are shown. The extremities created by $\mathrm{F} 1$ and $\mathrm{F} 2$ deoxyoligonucleotide-directed digestion in the SE element and in exon +1 are indicated in AF3 and AF10, respectively. The 9-nucleotide sequence inserted in AF8 $\Delta 1$ to generate AF $8 \Delta 1-9$ is indicated. $(B)$ In vitro splicing of several of the pre-mRNAs described in $A$. Splicing reactions were carried out for $2 \mathrm{hr}$ (lanes 1-10 and 19-21) or for the time (in hr) indicated above lanes 11-18, and the labeled RNAs were separated in $5 \%$ denaturing polyacrylamide gels. The positions of the pre-mRNAs (P), lariat products (I) and lariat intermediates (L) are indicated. Lariat intermediates were not produced in sufficient amount to be readily detected in lanes $12,14,17$, and 18. 


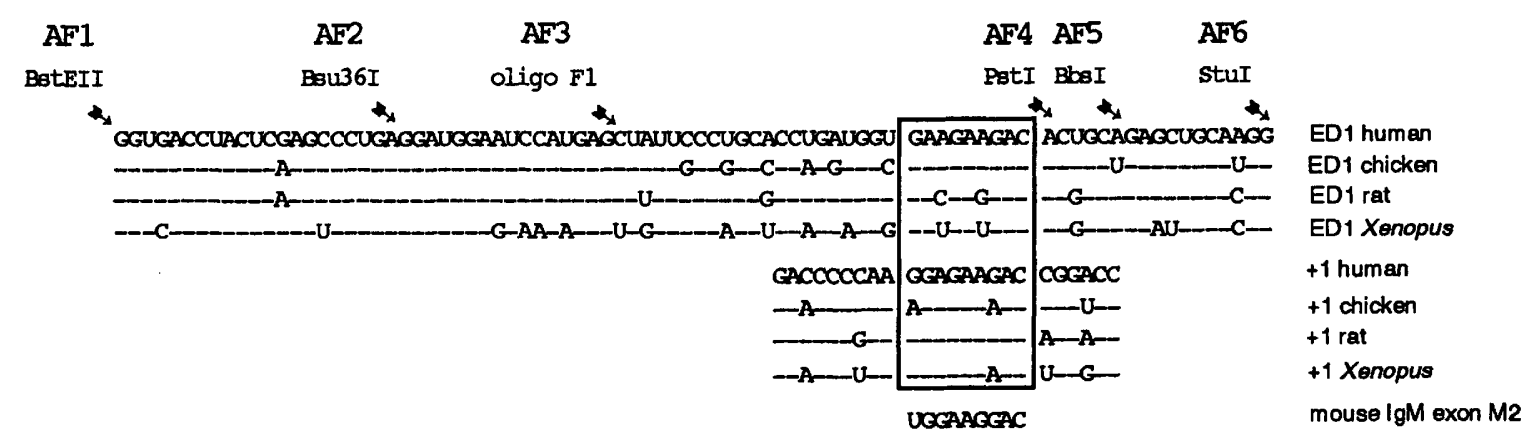

Figure 3. Comparison of fibronectin exons EDl and +1 sequences across species. The sequence of the complete SE element found in the human ED1 exon and defined by the BstEII and StuI restriction sites (Mardon et al. 1987) on the corresponding DNA is shown. The endpoints of several RNAs used in Fig. 2B are indicated by arrows. Equivalent regions in chicken, rat, and Xenopus ED1 exons are indicated below the human sequence. Nucleotides identical to human sequences are indicated by dashes. The sequence of the 21-nucleotide region of human exon +1 , which displays enhancing activity, is shown as well as the chicken, rat, and Xenopus corresponding sequences. The boxed area illustrates the 9-nucleotide purine-rich sequence shared by exons ED1 and +1 . The sequence of the recently described purine-rich region of exon M2 in the IgM pre-mRNA (Watakabe et al. 1993) is shown for comparison.

lane 6; data not shown). Weak splicing of AF7 11 and AF8 1 1 RNAs, which lacked all of the SE element (Fig. $2 \mathrm{~A}$ ), indicated that the rest of exon ED1, its associated 5' splice site, and intron sequences could not substitute for the SE element (Fig. 2B, lane 19; data not shown).

We also substituted the SE element for an internal region of the downstream constitutive exon +1 . AF10 and AF9 RNAs (Fig. 2A), which contains 80- and 21nucleotides of exon +1 , respectively, were spliced as efficiently as an RNA containing the complete SE element of EDl (Fig. 2B, lanes 11-18). Comparison of the 21-nucleotide sequence found in exon +1 with the essential 31-nucleotide region of the SE element in exon EDl revealed a conserved 9-nucleotide region rich in purines (Fig. 3).

To show conclusively that the purine-rich element was responsible for the stimulation of splicing, we inserted the 9-nucleotide sequence, GAAGAAGAC, at the corresponding BstEII site of AF8 1 1 (AF8D1-9 RNA; Fig. 2A). The 9-nucleotide sequence stimulated L1/ED1 splicing to a level equivalent to the complete SE element (Fig. 2B, lanes 19-21). This result demonstrates that the 9-nucleotide purine-rich sequence is sufficient to stimulate splicing at the upstream EDl 3' splice site.

\section{Position characteristics of the SE element in the ED1 exon}

Substitution of the SE element for a variety of sequences induced variable effects on Ll/EDl splicing (Fig. 4A). For example, an 88-nucleotide insert from the human $\beta$ globin second exon in reverse orientation (AFG1 RNA) failed to stimulate splicing above the level observed with AF2 RNA (Fig. 4B, lane 3). In contrast, a 139-nucleotide globin insert containing a nonfunctional $5^{\prime}$ splice site (Chabot and Steitz 1987b) stimulated splicing to a level comparable with that of AF6 RNA (AFG3 RNA; Fig. 4B, lane 7). Substitutions for a variety of $\phi X 174$ inserts affected splicing to an extent that ranged from complete inhibition to slight stimulation of splicing (Fig. 4B, lanes 9,11 ; Fig. 5B, lanes 5,6; data not shown).

Inserts that failed to stimulate L1/ED1 splicing were used to investigate the effect of displacing the SE element from its original position 99 nucleotides from the $3^{\prime}$ splice site to increasingly larger distances. This assay was accomplished by comparing the splicing efficiency of RNAs derived from DNA templates linearized at or near the $3^{\prime}$ end of the insert with the efficiency of the corresponding RNAs synthesized from StuI-cut DNA templates containing a complete SE element. Stimulation of Ll/EDl splicing at the authentic $3^{\prime}$ splice site was observed with inserts that moved the SE element to 187 and 293 nucleotides from the 3' splice site (AFG2 and AFX2 RNAs; Fig. 4B, lane 4; data not shown, respectively|. Notably, RNA substrates containing $\phi X 174$ inserts that moved the SE element 370 and 380 nucleotides from the ED1 3' splice site were spliced with efficiencies similar to those obtained with RNAs lacking the SE element (AFX3 to AFX6 RNAs; Fig. 4B, lanes 9-12). An inhibitory effect associated with the $\phi \times 174$ sequences is unlikely, as the inserts present in AFX3 and AFX5 RNAs do not interfere with the basal level of L1/ED1 splicing. Thus, although the SE element is active at considerable distance from its normal position, it failed to promote enhancement of splicing when located beyond $293 \mathrm{nu}$ cleotides from the EDI acceptor site.

Bringing the SE element 34 nucleotides from the ED1 3 ' splice site (AF15 RNA) resulted in a splicing efficiency superior to the efficiency observed with AF6 RNA (Fig. 4B, lane 15). In contrast, placing the SE element in the intron (250 nucleotides from the $3^{\prime}$ splice site; AF16 RNA) failed to improve splicing above the level seen with AF1 RNA (Fig. 4B, lane 16). The lack of effect was not the result of the increased size of the intron because providing an additional copy of the SE element at the authentic position in the exon stimulated splicing (Fig. $4 \mathrm{~B}$, lane 17). These results indicate that positioning the SE element at an appropriate distance downstream from the ED1 3' splice site is required for stimulation. 


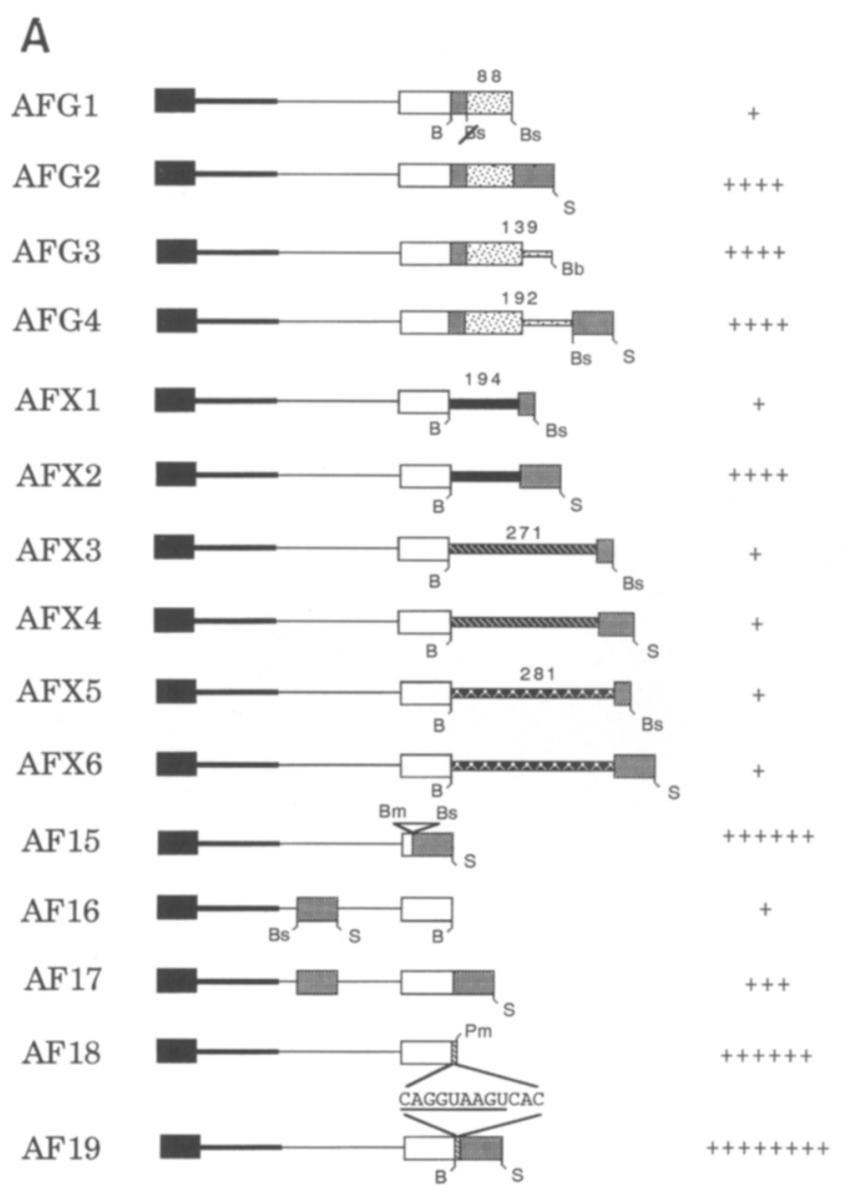

It has been reported that the presence of a $5^{\prime}$ splice site stimulates the utilization of upstream $3^{\prime}$ splice sites (Nasim et al. 1990; Watakabe et al. 1993). We tested whether the ED1 3' splice site could be stimulated by $5^{\prime}$ splice site sequences by substituting the SE element for a consensus 5' splice site (AF18 RNA; Fig. 4A). The splicing of AF18 RNA was more efficient than the splicing of AF6 RNA, which contains a complete SE element (Fig. $4 B$, cf. lane 19 with 20). Interestingly, an RNA substrate containing both a $5^{\prime}$ splice site and a downstream SE element (AF19; Fig 4A) was spliced with exceptionally high efficiency (Fig. 4B, lane 18). This result indicates that the SE element can stimulate an upstream 3' splice site even when positioned downstream from a $5^{\prime}$ splice site.

\section{The SE element stimulates splicing of other pre-mRNAs in vitro}

To test whether the SE element could stimulate splicing on heterologous $3^{\prime}$ splice sites, we inserted the SE element into the second exon of three different premRNAs. The first pre-mRNA examined was a human $\beta$-globin substrate (Fig. 5A). The first step of splicing of the simple human $\beta$-globin substrates is not influenced

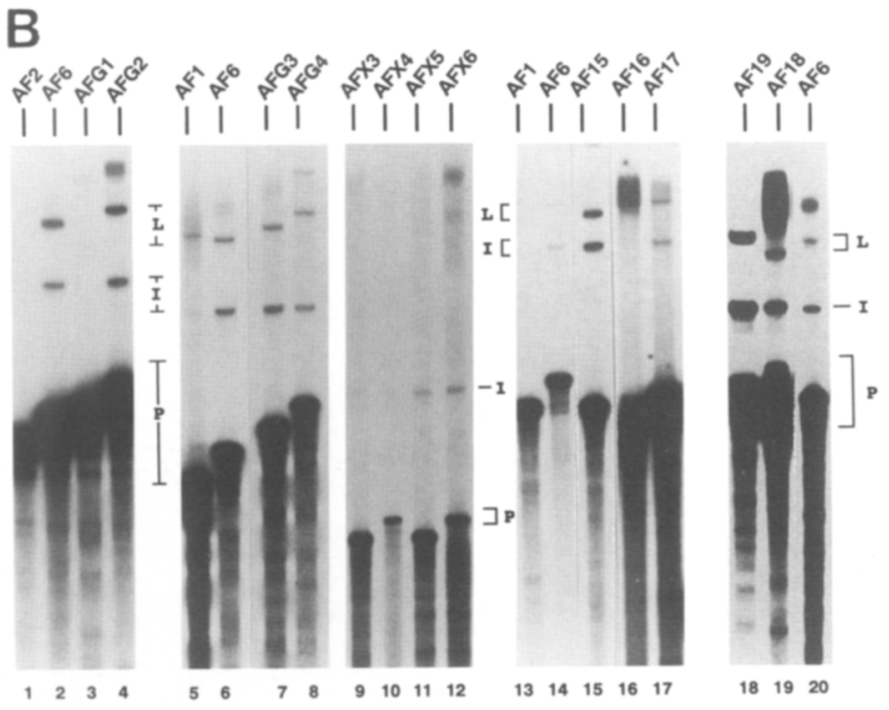

Figure 4. Insertion of heterologous sequences and displacement of the SE element. $(A)$ Diagram illustrating the RNA substrates used. The AFG series contains globin inserts as described in the text and in Materials and methods; the AFX series contains $\phi X 174$ inserts. The size of each insert is shown. The position of the restriction site PmlI (Pm) used to generate AF18 RNA is indicated. The sequence corresponding to the $5^{\prime}$ splice site consensus sequence is underlined. $(B)$ In vitro splicing of selected pre-mRNAs. Each set of premRNAs was incubated for $2 \mathrm{hr}$ in a HeLa extract. Labeled RNAs were separated on $5 \%$ denaturing polyacrylamide gels. The positions of the pre-mRNA (P), lariat intron (I), and lariat intermediate (L) are indicated. Note that the slower migrating species observed above the lariat intermediates in lanes 4, 5, 16, 19, and 20 are not splicing products, as they were detected nonreproducibly and were also seen in mixtures kept at $0^{\circ} \mathrm{C}$ (not shown).

by the size of the second exon, although the second step of splicing is impaired when the size of that exon is reduced to 14 nucleotides (Ruskin and Green 1985; Furdon and Kole 1986; Parent et al. 1987). Accordingly, a globin pre-mRNA containing 18 nucleotides as a second exon carried out only the first step of splicing (G2 RNA; Fig. $5 \mathrm{~B}$, lane 1). The overall splicing efficiency (step $1+$ step 2) of a globin RNA containing the SE element (GF1 RNA) was approximately three-fold higher than the efficiency observed with G2 RNA (Fig. 5B, cf. the sum of the intensities of the splicing products in lane 1 with the sum of $\mathrm{M1}, \mathrm{E}$, and I in lane 2). The globin transcript containing the SE element in reverse orientation (GF2 RNA) was spliced approximately sixfold less efficiently than GF1 RNA (Fig. 5B, cf. lane 2 with 3). We have not investigated further this apparent inhibition of splicing associated with the SE element in reverse orientation. The insertion of two SE elements (GF3 RNA) did not improve splicing above the level seen with GF1 RNA (Fig. 5B, lane 4) consistent with the results obtained with AF14 RNA (Fig. 1A). Note that increasing the size of the second exon allows the second step of the splicing reaction to occur for all GF RNAs.

In contrast to the globin substrate, insertion of the $\mathrm{SE}$ element in the adenovirus L2 exon (AAF1 RNA; Fig. 5A) 


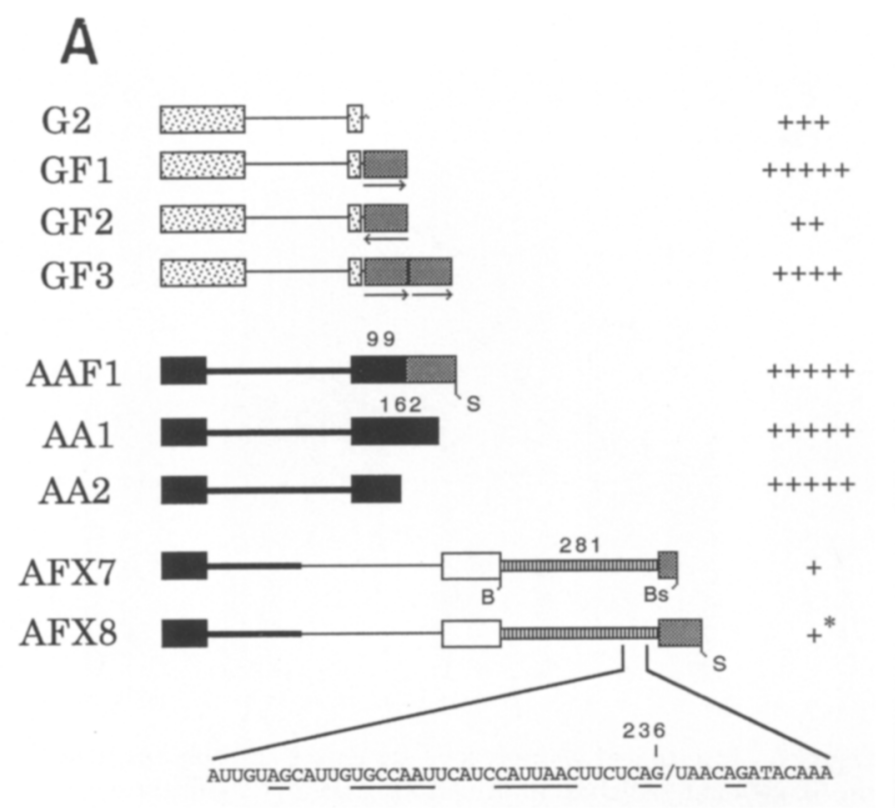

Figure 5. Insertion of the SE element into the second exon of heterologous pre-mRNAs. (A) Structure of the splicing substrates used to test the effect of the SE element on human $\beta$-globin splicing (GF1, GF2, and GF3 RNAs), adenovinus L1/L2 splicing (AAF1 and AAl RNAs), and a hybrid substrate containing 281-nucleotides of $\phi X 174$ sequences (AFX7 and AFX8 RNAs). For AFX7 and AFX8 RNAs, the score in splicing efficiency represents $\mathrm{L} 1 / \mathrm{EDl}$ splicing and the asterisk $\left({ }^{*}\right)$ indicates that a novel $3^{\prime}$ splice site is used with high efficiency in AFX8 RNA. The $\phi X 174$ sequence corresponding to the region used as a $3^{\prime}$ splice site is shown, and possible $3^{\prime}$ splice sites and branch site sequences that match the consensus YNYYRAY are underlined ( $Y=$ pyrimidines, $R=$ purines, and $N=$ any nucleotide). The use of the AG at position 236 in the $\phi X 174$ sequence would produce an mRNA of 193 nucleotide. $(B)$ In
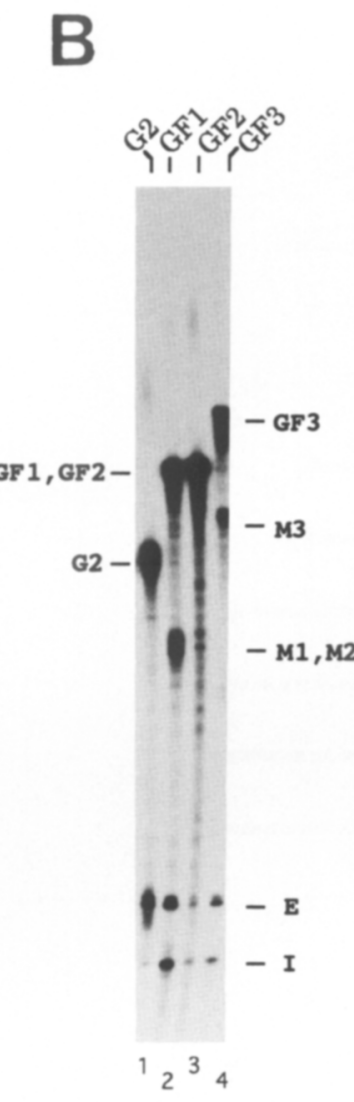

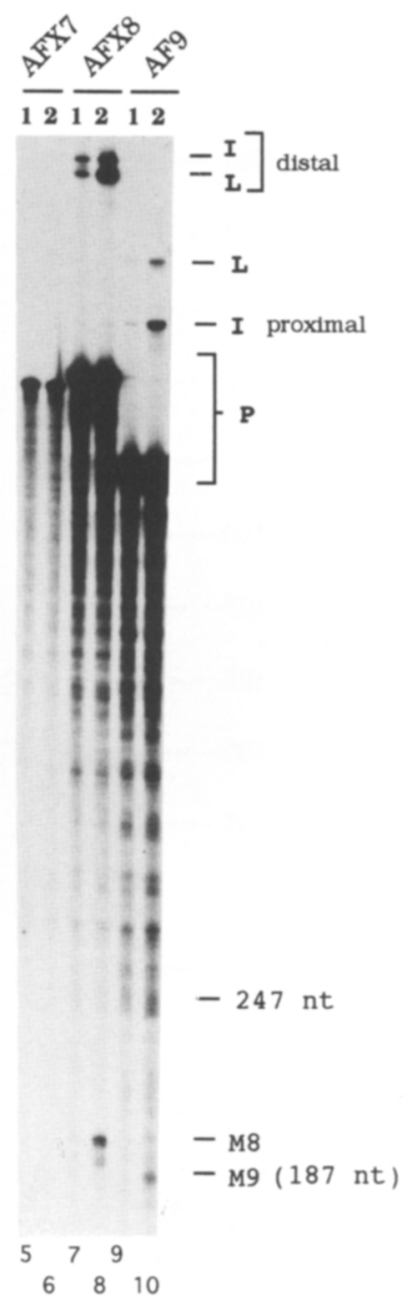
vitro splicing of pre-mRNAs containing the SE element in their second exon. Incubations were carried out for $2 \mathrm{hr}$ (G2, GF1, GF2, and GF3 RNAs; lanes 1-4) or for the time (in hr, top) indicated. (AFX7, AFX8, AF9 RNAs; lanes 5-10). (Left) The position of the globin pre-mRNA substrates (G2, GF1, GF2, and GF3) is indicated. M1, M2, and M3 correspond to the mRNAs produced from GF1, GF2, and GF3, respectively. The positions of the free 5' exon (E) and lariat intron (I) are also given. The positions of the lariat intermediates are obscured by the comigration with the free $5^{\prime}$ exon (lane 1 ) or the mRNAs (lanes 2-4). (Right) The positions of the pre-mRNAs (P) and lariat molecules corresponding to L1/ED1 splicing (I proximal and $\mathrm{L}$ ) and $\mathrm{L} 1 / \phi X 174$ splicing (I distal and $\mathrm{L}$ distal) are shown. The positions of the mRNA products derived from AFX 8 and AF9 splicing are also shown (M8 and M9, respectively). The position of a relevant molecular mass marker at 247 nucleotides is also indicated.

did not increase the already efficient L1/L2 splicing /data not shown). The most dramatic stimulation of splicing mediated by the SE element was obtained with a $\phi \times 174$ derivative of the L1-EDl construct. AFX7 and AFX8 RNAs (Fig. 5A) contain a 281-nucleotide $\phi X 174$ insert in reverse orientation compared with AFX5 and AFX6 RNAs (Fig. 4A). This prokaryotic insert did not stimulate L1/ED1 splicing nor did the insertion of an SE element downstream of the $\phi X 174$ sequence improve L1/ED1 splicing (Fig. 5B, lanes 5-10), consistent with our previous observations indicating an upper limit in the distance separating the SE element from the EDl acceptor site. Remarkably however, a novel 3' splice site was activated in AFX8 RNA, as judged by the presence of slower migrating lariat molecules. The size of the corresponding mRNA band at $\sim 200$-nucleotides indicated that splicing occurred at a $3^{\prime}$ splice site located $\sim 230$ nucleotides into the $\phi X 174$ sequences. Inspection of the $\phi X 174$ sequences revealed a respectable fit to the consensus branch site and 3' splice site in that region (see Fig. 5A). Thus, the SE element promoted with high efficiency the utilization of a previously unused $3^{\prime}$ splice site in vitro. These results show that the SE element stimulates in vitro splicing on heterologous pre-mRNAs with varying efficiencies. In the pre-mRNAs tested, the weaker the efficiency of utilization of a given $3^{\prime}$ splice site was, the stronger was splicing at that site stimulated by the SE element.

\section{The SE element affects U2 snRNP binding}

To understand the mechanism by which the SE element 
mediates enhancement of splicing, we investigated which step of spliceosome assembly was stimulated by the SE element. Analysis of splicing complexes on native gels using AF1, AF2, AF3, AF4, and AF6 RNAs indicated poor complex $A$ formation in the absence of the ED1 sequence essential for splicing stimulation (Fig. 6A). Thus, the formation of early splicing complexes is stimulated by the SE element and the extent of stimulation paralleled the enhancement of splicing. The SE element also stimulated splicing complex formation on human $\beta$-globin RNA (using G2, GF1, and GF2 RNAs; data not shown).

Complex A represents a pre-spliceosomal assembly that contains U2 snRNP. To confirm that U2 snRNP binding was occurring more efficiently in the presence of the SE element, we performed an RNase T1 protection/ immunoprecipitation assay with the monoclonal antibody Y12, which recognizes the Sm epitope present on most snRNPs (Hinterberger et al. 1983). Because the identity of the U2 snRNP-protected fragments in such an assay was obtained previously with human $\beta$-globin premRNAs (Chabot and Steitz 1987a), we used the globin G2 RNA and its fibronectin derivatives, GF1 and GF2 RNAs, to evaluate the influence of the SE element on U2 snRNP binding. When performed on the $\beta$-globin substrate G2, this assay revealed a prominent protection at the 5 ' splice site mediated by Ul snRNP (fragment A, 15 nucleotides); and upon incubation at $30^{\circ} \mathrm{C}$, the appearance of branch site protected fragments bound by U2 snRNP (fragments E and D, 42 and 35 nucleotides, respectively) (Fig. 6B, lanes 1-4) (Chabot and Steitz 1987a). The protection assay was also performed on GFl and GF2 RNAs, which contain the SE element in normal and inverted orientation, respectively. The presence of the SE element stimulated splicing approximately threefold (GF1; Fig. 5). Correspondingly, branch site-protected fragments $E$ and $D$ were immunoprecipitated three times more efficiently with GF1 RNA than with G2 or GF2 RNAs (Fig. 6B, lanes 1-12). Comparable U1 snRNP binding at the $5^{\prime}$ splice site (fragment A) was observed with all substrates. These results indicate that U2 snRNP binding at the branch site is improved when the SE element is present in the globin second exon.

\section{Trans-acting factors mediate enhancement via the SE element}

To address the possibility that the SE element might interact with trans-acting factors to mediate enhancement of splicing, we performed competition experiments using increasing molar excesses of a 140-nucleotide RNA containing the SE element (SE RNA). Partial inhibition of AF6 RNA splicing was observed with as little as 10-fold molar excess while complete inhibition was obtained with a 150-fold excess of SE RNA (Fig. 7, lanes 1-5). In contrast, the SE RNA did not interfere with adenovirus (AA2) RNA splicing even when present in a 150-fold excess (Fig. 7, lanes 9-13). In addition, competition with an RNA derived from sequences that did not substitute for the SE element (SN RNA; see Fig. 2A,
Splicing enhancer in the fibronectin ED1 exon
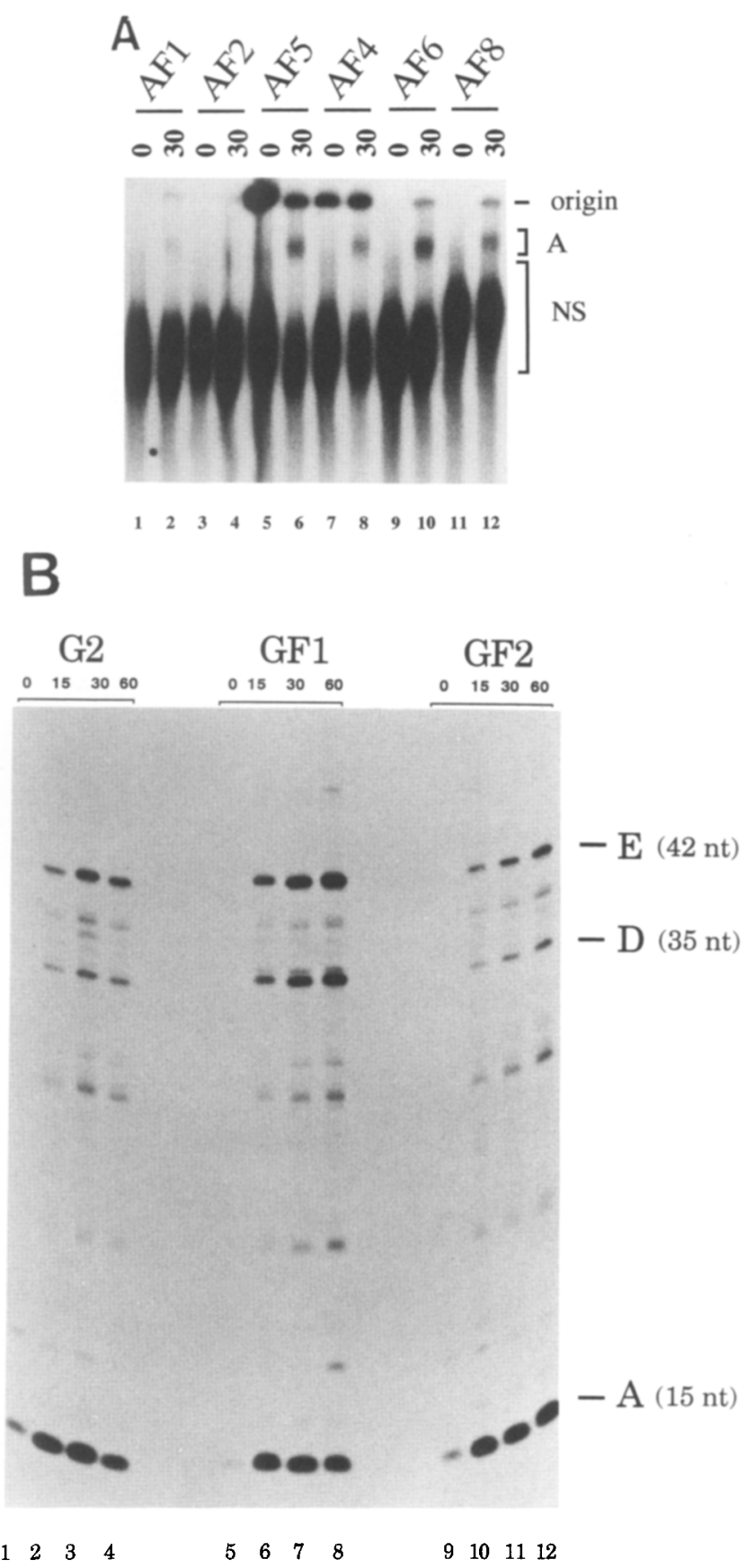

Figure 6. Interaction of splicing factors on pre-mRNAs containing or lacking the SE element. $(A)$ Analysis of splicing complex formation by native gel electrophoresis. Pre-mRNAs, the structures of which are illustrated in Figure 3A, were incubated under splicing conditions for the time (in min, top) indicated. The reaction mixtures were then put on ice, adjusted to 500 $\mu \mathrm{g} / \mathrm{ml}$ of heparin, and loaded onto a $4 \%$ native gel. Nonspecific (NS) and A complexes are indicated. (B) RNase T1 digestion/ immunoprecipitation assays. The globin pre-mRNA (G2) and derivatives (GF1 and GF2) were incubated for the time (in min, top) indicated. RNase $\mathrm{T} 1$ digestion and anti-snRNP (Y12) immunoprecipitation were performed according to Chabot and Steitz (1987a). The positions of the 15 -nucleotide $5^{\prime}$ splice site protected fragment (fragment A) bound by Ul snRNP and the branch site sequences protected by U2 snRNPs (fragments $E$ and D) are indicated and correspond to fragments characterized in Black et al. (1985) and Chabot and Steitz (1987a). 


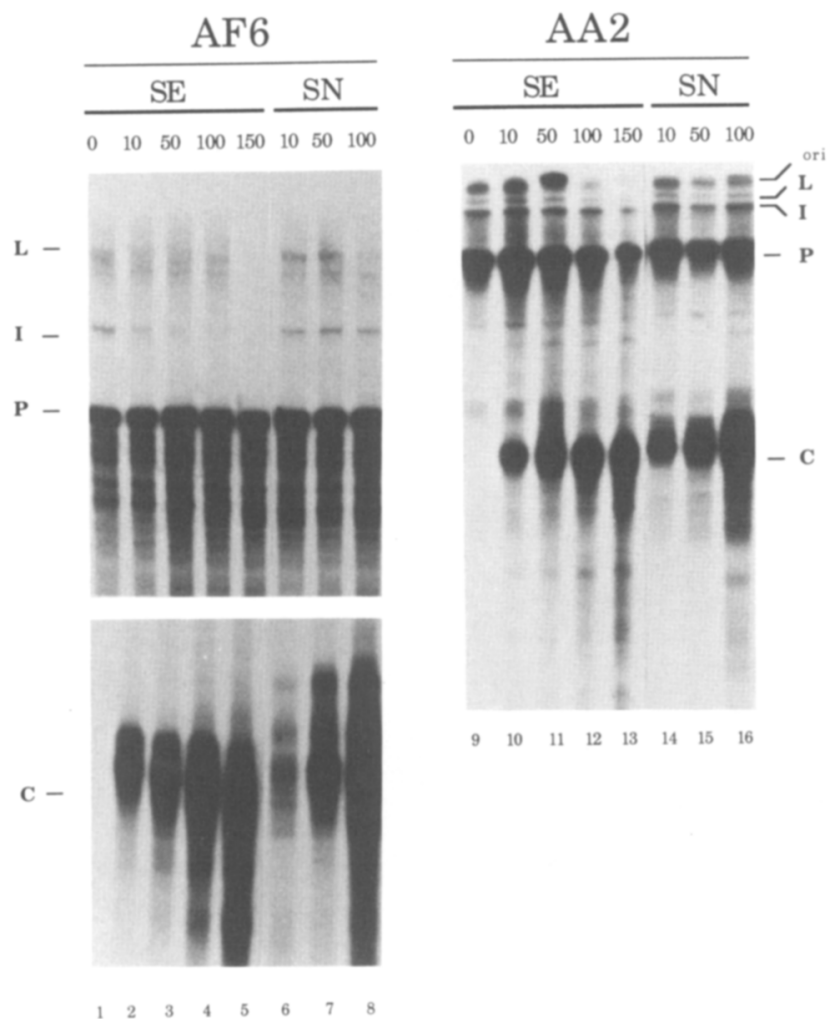

Figure 7. Inhibition of in vitro splicing by competition with the SE element. The HeLa extract was preincubated with no RNA (lanes 1,9), increasing amounts of an RNA containing the SE sequences (lanes 2-5, 10-13), or a nonspecific RNA (SN; lanes 6-8, lanes 14-16) derived from a region defined by the StuI and $\mathrm{NcOI}$ sites in AF7 (see Fig. 2A) that does not substitute for the SE element in in vitro splicing assays (lanes $6-8,14-16$ ). The SE RNA contains the complete SE element plus 64 nucleotides at the $5^{\prime}$ end that are derived from the transcription template. Following preincubation with the competitor RNA, the AF6 RNA (lanes 1-8) and the adenovirus AA2 RNA (lanes 9-16) were incubated for $2 \mathrm{hr}$ and the splicing products fractionated as described earlier. The molar excess of each competitor is indicated at the top of each lane. Because the competitor was labeled at $1 / 100$ of the specific activity of the pre-mRNA substrate, it was possible to visualize it in the reaction mixtures. The positions of the pre-mRNA $(\mathrm{P})$, lariat product (I), lariat intermediate $(\mathcal{L})$, and competitor $(C)$ are indicated. Note that the sample loaded in lane 13 was partially lost.

AF7 1 RNA) did not reduce the splicing efficiency of either AF6 or AA2 RNAs (Fig. 7, lanes 6-8 and 14-16, respectively). Thus, an excess of the SE RNA was sufficient to inhibit AF6 RNA splicing completely and specifically. A similar inhibition profile was also observed with the $\beta$-globin derivative GF1 (data not shown). These results indicate that factors bind to the SE element to stimulate splicing.

\section{$S R$ proteins bind to the SE element}

To detect the interaction of nuclear factors with the SE element, we performed an RNA mobility shift assay us- ing SE RNA, which is identical to the transcript used in competition assays, and SE $\triangle$ Pu RNA, which lacks the sequences essential for enhancer activity. Each RNA was incubated in splicing mixtures at $0^{\circ} \mathrm{C}$, and RNA-protein complexes were separated in nondenaturing polyacrylamide gels. As can be seen in Figure 8, the migration of SE RNA was considerably retarded when incubated in a HeLa nuclear extract (Fig. 8, lane 3). In contrast, incubation of SE RNA in a HeLa S-100 extract provoked no shift in mobility (Fig. 8, lane 5). SE $\triangle$ Pu RNA did not stably associate with factors, as it migrated as naked RNA following incubation in either nuclear or S-100 HeLa extracts (Fig. 8, lanes 4,6). This result suggests that factors present in the nuclear but not the S-100 extract are responsible for the specific shift observed with SE RNA. S-100 extracts are deficient in splicing, but splicing activity can be restored by supplemention with SF2/ASF, SC35, or any other member of the SR family of proteins (Krainer et al. 1990a; Mayeda et al. 1992; Zahler et al. 1993b). The lower abundance of SR proteins in S-100 extracts suggested that SR proteins interact with the SE element. Purified SR proteins from calf thymus specifically shifted SE RNA to a position that was comparable to the retardation obtained with a HeLa nuclear extract

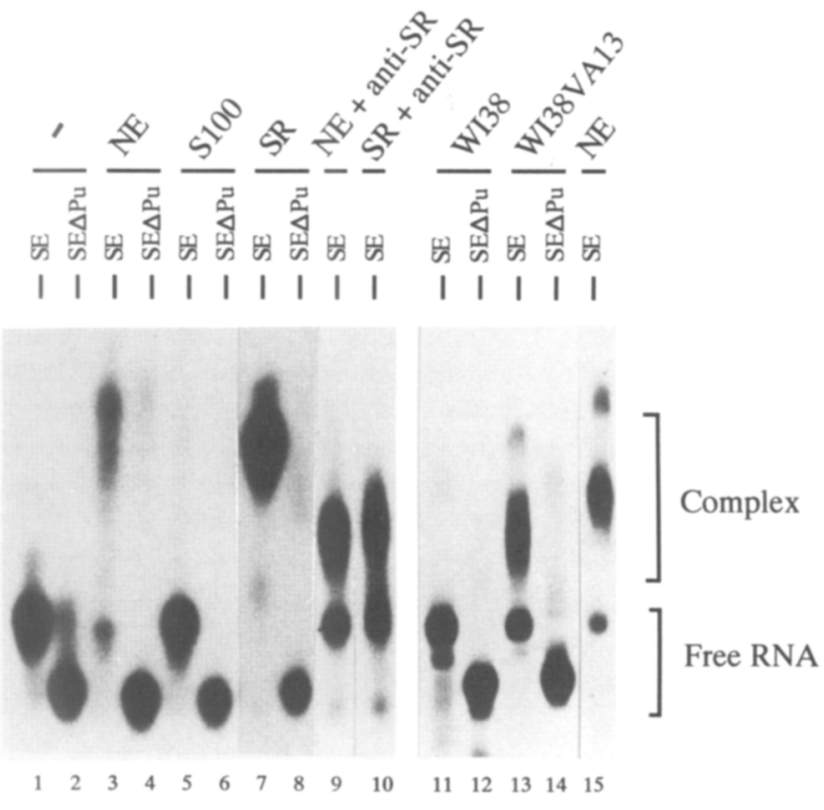

Figure 8. SR proteins bind to the SE element. SE RNA (140 nucleotides) is identical to the splicing competitor used in Fig. 7. SE $\triangle \mathrm{Pu}$ is a shorter version of SE RNA that lacks the last 45 nucleotides at the $3^{\prime}$ end of the SE element. ${ }^{32}$ P-Labeled RNAs were incubated at $0^{\circ} \mathrm{C}$ with $3 \mu \mathrm{l}$ of HeLa nuclear extract $(\mathrm{NE}$; lanes $3,4,9,15), 3 \mu \mathrm{l}$ of HeLa $\mathrm{S} 100$ extract $(\mathrm{S} 100$; lanes 5,6), $2 \mu \mathrm{l}$ of purified SR proteins from calf thymus $\left(\mathrm{SR}_{\text {; }}\right.$ lanes $\left.7,8,10\right)$ or with nuclear extracts from WI38 $\left(3 \mu l_{;}\right.$lanes 11,12) and WI38VAl3 $(2 \mu \mathrm{l}$; lanes 13,14$)$ cells. In lanes 9 and $10,1 \mu \mathrm{l}$ of mAbl04 specific to SR proteins (Zahler et al. 1992) was added to the mixtures. RNA-protein complexes were separated on nondenaturing $8 \%$ polyacrylamide gels containing $5 \%$ glycerol. The positions of the free RNAs and complexes are indicated. 
(Fig. 8, lanes 7,8). The binding of SR proteins to the SE element was confirmed in two ways. First, the addition of a monoclonal antibody specific to SR proteins (mAb104; a kind gift of $M$. Roth, Fred Hutchinson Cancer Research Center, Seattle, WA) to either a HeLa nuclear extract or to our SR protein preparation altered the mobility of the complexes formed with SE RNA (Fig. 8, lanes 9,10). The faster migration of the complexes formed in the presence of the antibody suggests that SR proteins assemble as multimers on SE RNA and that the antibody interferes with this process. Second, extracts prepared from human WI38 cells display a profound reduction in SF2/ASF activity compared with their transformed derivative WI38VA13 (Chabot et al. 1992). In an RNA mobility shift assay, only the WI38VA13 extract promoted a specific shift in the mobility of SE RNA (Fig. 8, lanes 11-14). The difference in migration of the complex between a WI38VA13 and a HeLa nuclear extract for purified SR proteins) likely reflects a difference in the concentration of SR proteins (data not shown). Our results demonstrate that SR proteins interact specifically with the SE element of the fibronectin ED1 exon.

\section{Discussion}

\section{The SE element is an enhancer of splicing}

The fibronectin alternate exon ED1 was originally reported to contain sequences that participate in splice site selection because deletion or inversion of an internal 81nucleotide segment (SE element) abolished exon ED1 inclusion in HeLa cells (Mardon et al. 1987). The results presented in this paper confirm and extend this observation considerably in vitro. First, the SE element markedly activates the use of the EDl 3 ' splice site. Second, the SE element could be moved to several positions downstream or upstream from its normal location without losing its ability to stimulate the use of the 3 ' splice site of ED1. Specifically, bringing the SE element to a closer location relative to the $3^{\prime}$ splice site promoted more efficient splicing than having the SE element in its original position. In addition, displacing the SE element up to 293 nucleotides from the $3^{\prime}$ splice site did not reduce splicing. The enhancing activity of the SE element was thus resistant to the removal of exon sequences flanking the SE element and remained unaffected by the insertion of several kinds of heterologous sequences. These results suggest that the SE element is not involved in the formation of essential secondary structures with other ED1 exon sequences. Our observations contrast with the usual characteristics of mammalian exon sequences, as manipulations introduced into almost any region of other alternate exons provoked important changes in exon splicing in vivo and, when tested, in vitro (Hampson et al. 1989; Streuli and Saito 1989; Libri et al. 1990; Black 1991; Tacke and Goridis 1991; Black 1992; Cooper 1992; Cote et al. 1992; Graham et al. 1992). Thus, the SE element of the fibronectin EDl exon is rather exceptional among mammalian exon elements in its ability to efficiently promote $3^{\prime}$ splice site recognition even following considerable molecular surgery on flanking exon sequences.

An additional but related feature of the SE element is its ability to stimulate splicing of heterologous pre-mRNAs. The most dramatic stimulation mediated by the SE element occurred on AFX8 RNA in which it induced the utilization of a pseudo- $3^{\prime}$ splice site in prokaryotic $\phi X 174$ sequences. The SE element also improved $\beta$-globin splicing threefold, but insertion of the SE element into the adenovirus second exon did not stimulate L1/L2 splicing. The strength of the $3^{\prime}$ splice site tested thus appears to be critical in determining the enhancing effect of the SE element because there is an inverse correlation between splicing efficiency of the test premRNA and the extent of stimulation by the SE element. The ability of exon sequences to stimulate a heterologous $3^{\prime}$ splice site in vitro is a property shared with the repeated exon elements of the Drosophila doublesex female-specific exon (Tian and Maniatis 1992) and the recently described exon recognition sequence (ERS) identified in a murine IgM pre-mRNA (Watakabe et al. 1993).

We have shown that the 9-nucleotide purine-rich sequence GAAGAAGAC, located within the SE element in the ED1 exon, is sufficient to promote stimulation of splicing. We have also identified a similar enhancer sequence in the downstream constitutive exon +1 (GGAGAAGAC). The 9-nucleotide sequence is not perfectly conserved in the EDl exon of other species, as the corresponding sequence of the rat and Xenopus EDl exon contains one and two pyrimidine substitutions, respectively (Fig. 3). In Xenopus however, purine substitutions in upstream sequences create an extensive purine stretch (AGAAGGGGAA) with slightly shifted position by comparison with the human purine-rich element. The purine-rich region of the exon +1 is well conserved across species (Fig. 3). Purine-rich domains containing a stretch of 7-9 purines were present in human $\beta$-globin and adenovirus inserts that substituted for the SE element (AFG3 RNA; data not shown). Such extensive purine stretches were lacking in globin and prokaryotic inserts that did not substitute for the SE element (AFG1 RNA; data not shown). Interestingly, replacement of the SE element by fibronectin intron sequences that included an 8-nucleotide stretch of purines/data not shown) did not restore efficient splicing. This result suggests that the presence of a long purine stretch is not in itself sufficient for stimulation and points toward other requirements that must be respected to maintain the enhancing activity. Investigating the contribution of nucleotides at every position of the purine-rich element should address this issue. It is also possible that sequestration of the purine-rich element into an RNA secondary structure abrogates the enhancing activity.

Recently, the mouse IgM exon M2 and the cardiac troponin $\mathrm{T}$ exon 5 were also identified as containing a purine-rich sequence (ERE and ESE, respectively) associated with the stimulation of $3^{\prime}$ splice site utilization (Watakabe et al. 1993; Xu et al. 1993). Watakabe et al. (1993) have noted that purine-rich stretches are found in a number of constitutive exons as well as in exons reg- 
ulated by alternative splicing. Because the $3^{\prime}$ splice sites of regulated exons are often suboptimal, the presence of a purine-rich stretch in the downstream exon may be an integral component of the recognition process of weak $3^{\prime}$ splice sites.

\section{Mechanism of activation}

The ability of the SE element to stimulate an upstream $3^{\prime}$ splice site is associated with more efficient complex formation and increased $\mathrm{U} 2$ snRNP binding at the branch site. On the other hand, the competition experiments indicated that trans-acting factors bind specifically to the SE element in the EDl exon to mediate stimulation of splicing. We showed that SR proteins interact specifically with the SE element. SR proteins constitute a group of at least six proteins [SRp20, SRp30a (SF2/ASF), SRp30b (PR264/SC35), SRp40, SRp55 and SRp75] with interchangeable function, as each protein can restore activity to a splicing-defective S-100 extract (Fu et al. 1992; Zahler et al. 1992,1993b). The SR proteins are required for complex A formation (Krainer et al. 1990b; Fu and Maniatis 1992). Moreover, SC35 (SRp30b) promotes stable U2 snRNP binding to the branch site by mediating an interaction with the U1 snRNP (Fu and Maniatis 1992). Thus, the stimulation in U2 snRNP binding mediated by the SE element is consistent with a model in which the SR proteins bound to the exonic sequence GAAGAAGAC promotes the interaction of $\mathrm{U} 2$ snRNP with the branch site region through a process that may involve $U 1$ snRNP.

Certain structural and functional features of the SE element are reminiscent of other downstream elements that activate $3^{\prime}$ splice sites. The stimulation of $3^{\prime}$ splice site utilization by a downstream $5^{\prime}$ splice site has recently been addressed in splicing studies on the preprotachykinin pre-mRNA (Nasim et al. 1990; Grabowski et al. 1991; Kuo et al. 1991; Hoffman and Grabowski 1992). In this case, U1 snRNP binding to a strong downstream $5^{\prime}$ splice site promotes $\mathrm{U}_{2} \mathrm{AF}^{65}$ binding by a network of interactions that remain to be understood (Hoffman and Grabowski 1992). Interestingly, both SE element and downstream 5 ' splice sites are unable to stimulate splicing when located beyond $\sim 300$-nucleotides from the $3^{\prime}$ splice site (Robberson et al. 1990). This value may represent a topological constraint affecting the ability of any downstream element to communicate with a 3 ' splice site and may not necessarily be indicative of an identical underlying mechanism. More recently, a purine-rich sequence (ERS) that stimulates splicing to the upstream 3' splice site of IgM exon M2 was cross-linked to the $5^{\prime}$ end of Ul snRNA in a HeLa extract (Watakabe et al. 1993). Consequently, a similar mechanism of activation involving U1 snRNP and leading to improved U2AF binding may be suggested for the purine-rich ERS element.

It is possible that the purine-rich element in the EDI exon also functions through a mechanism that involves U1 snRNP and U2AF. Substitution of the SE element for a consensus $5^{\prime}$ splice site led to strong stimulation of splicing, suggesting that improving U2AF binding at the $3^{\prime}$ splice site of ED1 led to more efficient splicing. $\mathrm{U} 2 \mathrm{AF}^{65}$ cross-linking assays have revealed an occasional stimulation associated with the presence of the SE element (data not shown). However, several results suggest that the situation may be more complex. First, the magnitude of the difference in U2AF cross-linking remained at least threefold lower than the difference in complex formation and splicing (data not shown). Second, whereas two copies of the SE element did not work better than one, the combination of an SE element and a $5^{\prime}$ splice site stimulated splicing even more than each element taken alone. These results suggest that distinct modes of stimulation are mediated by $5^{\prime}$ splice site and purine-rich sequences. Third, we have been unable to detect U1 snRNP binding to the SE element that would be as strong as Ul snRNP binding to a $5^{\prime}$ splice site /data not shown). Although an indirect interaction of U1 snRNP with the SE element may be less stable, a weak U1 snRNP interaction is unlikely to be sufficient to stimulate $\mathrm{U}_{2} \mathrm{AF}^{65}$ binding, as mutated or weak downstream $5^{\prime}$ splice sites seriously compromise $\mathrm{U}^{2} \mathrm{AF}^{65}$ binding and 3 ' splice site utilization (Talerico and Berget 1990; Hoffman and Grabowski 1992). A more extensive characterization of the factors that associate with the SE element should help to clarify the role of U2AF, U1 snRNP, and additional factors in the activation pathway mediated by the purine-rich element of the ED1 exon.

\section{Regulation of ED1 alternate splicing by the SR proteins}

Although the biological significance of SR proteins binding to the SE element remains to be established, this finding may have important implications in the regulation of ED1 alternative splicing. First, SR proteins are known alternative splicing factors in vitro. Specifically, increases in the concentration of SR proteins promote proximal shifts in the selection of $5^{\prime}$ and $3^{\prime}$ splice sites (Krainer et al. 1990a; Fu et al. 1992; Zahler et al. 1993a) as well as exon inclusion (Mayeda et al. 1993). SR proteins, in cooperation with Tra and Tra-2, have also been shown recently to associate specifically with exon elements in the doublesex pre-mRNA to mediate femalespecific splicing (Tian and Maniatis 1993). Whereas the identification of a purine-rich enhancer in the downstream constitutive exon +1 of fibronectin is surprising, it is not inconsistent with a role for the SE element in the regulation of ED1 alternative splicing, as variations in the concentration of SR proteins differentially affect the use of identical competing splice sites (Krainer et al. 1990a; Mayeda and Krainer 1992; Mayeda et al. 1992). Second, nuclear extracts prepared from cells (e.g., WI38 and WI38VA13) that splice the fibronectin ED1 exon differentially display a difference in SR protein activity (Chabot et al. 1992). On the basis of these considerations, we anticipate that the interaction of SR proteins with the GAAGAAGAC sequence will be of paramount importance in establishing cell-specific splicing profiles for the ED1 exon. Future investigations will address this issue and identify which SR proteins interact with the purine-rich sequence of the fibronectin EDl exon. 


\section{Materials and methods}

\section{Plasmid constructions and RNA substrates}

The plasmid pAdED used to generate transcripts AF1-AF8 was constructed by inserting a DraI 666-bp human genomic fragment including the ED1 exon and parts of the two flanking introns into pSPAd (Chabot et al. 1992) containing a StuI linker at the HindIII site (pSPAdStu). AFAl and AFA2 RNAs were produced from pAdED in which either the BstEII-EcoRI or the StuI-EcoRI fragment was substituted for the StuI-EcoRI fragment of pSPAdStuI.

The plasmid T11-9 used to generate AF5 11 RNA was constructed by religating pAdED cut with BstEII and Bsu36I, which were end filled previously with Klenow. Other internal deletions in the fibronectin segment of pAdED used to generate transcripts $A F 7 \Delta 1$ and $A F 8 \Delta 1$ were obtained by religating pAdED end-filled with Klenow, after cutting with BstEII and StuI or BstEII and NcoI, respectively. The plasmid pFl used to generate the transcript AF14 was obtained by inserting the BstEII-StuI 81-bp EDl fragment into pAdED cut with Bsu36I. The plasmid pAdED +1 used to generate the transcripts AF9 and AF10 was obtained by substituting the BstEII-EcoRI fragment of ED1 for BstEII-EcoRI fragment containing exon +1 sequences. To construct pAF8 $\Delta 1-9$, the EDPU-1 and EDPU-2 oligonucleotides were annealed and ligated at the BstEII site of pAF8 $\Delta 1$. The correct structure of pAF8 $\Delta 1-9$ was confirmed by sequencing. To generate pGF1, pGF2, and pGF3, we inserted the Bsu36I-StuI fragment into the StuI site of a modified $\mathrm{pH} \beta \Delta 6$ (Krainer and Maniatis 1985) in which the globin AccI fragments had been deleted and replaced by a StuI linker. pAAF1 was produced by substituting the $1.8 \mathrm{-kb}$ fibronectin BstEII fragment for the HincII fragment in pSPAd. pAFGa used to produce AFG1 and AFG2 RNAs was obtained by insertion of a 98-bp globin fragment into the Bsu36I site in pAdED. pAFGb, which produced AFG3 and AFG4 RNAs, was obtained by insertion of a 192-bp Bsu36I fragment at the same site in pAdED. pAdEDiSE used to generate AF16 and AF17 RNAs was obtained by cloning the BstEII-SmaI fragment of pAdED into the StuI site of pSPAdStu, followed by insertion of the 666-bp DraI fragment at the StuI site of the SE element. pAdED5' used to produce AF18 and AF19 RNAs was obtained by annealing and ligating oligonucleotides CONS-1 and CONS-2 into the BstEII site of pAdED.

The series of pAFX plasmids were all obtained by cloning a mixture of HaeIII-digested fragments from $\phi X 174$ DNA into the filled BstEII site of pAdED. SE RNA was produced from a StuIcut pKFNB that contained the fibronectin 1.5 -kb Klenow-filled BstEII fragment inserted at the EcoRV site of pBluescript $\mathrm{KS}(+)$ (Stratagene). SN RNA was produced from a plasmid containing the fibronectin StuI-BamHI fragment linearized at the NcoI site.

\section{Deoxyoligonucleotides}

The oligonucleotides used in directed digestion by RNase $\mathrm{H}$ were F1 (CAGGTGCAGGGAATA) and F2 (GGGGTCACCCGCACTCGATAT). EDPU-1 (GTGACCGAAGAAGACG) and EDPU-2 (GTCACCGTCTTCTTCG) were partially complementary. CONS-1 (GTGACCAGGTAAGTCAC) was partially complementary to CONS-2 (GTCACGTGACTTACCTG).

\section{In vitro transcription and splicing reactions}

Splicing substrates were synthesized as described previously (Chabot et al. 1992). For oligonucleotide-directed digestion with RNase $\mathrm{H}, 0.1 \mu \mathrm{g}$ (15 pmoles) of deoxyoligonucleotide and $1 \mu \mathrm{l}$ of RNase $\mathrm{H}$ (Pharmacia) were added in transcription mixtures.
HeLa nuclear and S-100 extracts were prepared according to Dignam et al. (1983), and splicing reactions were set up as described previously (Krainer and Maniatis 1985). Competition experiments were performed as described in Black (1992).

\section{Native gels}

Electrophoretic separation of splicing complexes was accomplished as described in Chabot et al. (1992). RNA mobility-shift assays were accomplished by incubating the transcripts in splicing mixtures for at least $10 \mathrm{~min}$ on ice. Heparin was added to a final concentration of $2 \mathrm{mg} / \mathrm{ml}$ before loading onto a $8 \%$ polyacrylamide gel (acrylamide/bisacrylamide, 29:1) containing 5\% glycerol. Gels were prerun for $30 \mathrm{~min}$ and run $2-3 \mathrm{hr}$ at $12 \mathrm{~V} / \mathrm{cm}$ at room temperature. SR proteins were prepared from calf thymus as described in Zahler et al. (1992).

\section{Immunoprecipitation and RNase $T 1$ protection assays}

Splicing reactions $(25 \mu l)$ were prepared and incubated for different times. RNase $\mathrm{Tl}$ protection/immunoprecipitation assay was performed as described in Black et al. (1985) and Chabot et al. (1985).

\section{Acknowledgments}

We are grateful to J. Beaudoin, A. Dorais, and D. Frappier for the production of several plasmids used in this study and to M.B. Roth and J.A. Steitz for antibodies. We thank P. Norton for sharing sequence information, and N. Sonenberg and I. Eperon for comments on the manuscript. This work was supported initially by a grant from the Medical Research Council (MRC) of Canada and later by the National Cancer Institute of Canada with funds from the Canadian Cancer Society to B.C.. A.L. is supported by a fellowship from the Cancer Research Society Inc. B.C. is a Research Scholar of the MRC of Canada.

The publication costs of this article were defrayed in part by payment of page charges. This article must therefore be hereby marked "advertisement" in accordance with 18 USC section 1734 solely to indicate this fact.

\section{References}

Black, D.L. 1991. Does steric interference between splice sites block the splicing of a short c-src neuron-specific exon in non-neuronal cells? Genes \& Dev. 5: 389-402.

Black, D.L., B. Chabot, and J.A. Steitz. 1985. U2 as well as U1 small nuclear ribonucleoproteins are involved in premessen. ger RNA splicing. Cell 42: 737-750.

1992. Activation of c-src neuron-specific splicing by an unusual RNA element in vivo and in vitro. Cell 69: 795-807.

Chabot, B. and J.A. Steitz. 1987a. Multiple interactions between the splicing substrate and small nuclear ribonucleoproteins in spliceosomes. Mol. Cell Biol. 7: 281-293.

. 1987b. Recognition of mutant and cryptic $5^{\prime}$ splice sites by the U1 small nuclear ribonucleoprotein in vitro. Mol. Cell. Biol. 7: 698-707.

Chabot, B., D.L. Black, D.M. LeMaster, and J.A. Steitz. 1985. The $3^{\prime}$ splice site of pre-messenger RNA is recognized by a small nuclear ribonucleoprotein. Science 230: 1344-1349.

Chabot, B., D. Frappier, and H. La Branche. 1992. Differential ASF/SF2 activity in extracts from normal WI38 and transformed WI38VA13 cells. Nucleic Acids Res. 20: 5197-5204.

Clouet, O., Y. d'Aubenton Carafa, P. Sirand-Pugnet, M. Gallego, E. Brody, and J. Marie. 1991. RNA secondary structure re- 
pression of a muscle-specific exon in HeLa cell nuclear extracts. Science 252: 1823-1828.

Cooper, T.A. 1992. In vitro splicing of cardiac troponin T precursors. Exon mutations disrupt splicing of the upstream intron. J. Biol. Chem. 267: 5330-5338.

Cote, G.J., D.T. Stolow, S. Peleg, S.M. Berget, and R.F. Gagel. 1992. Identification of exon sequences and an exon binding protein involved in alternative RNA splicing of calcitonin/ CGRP. Nucleic Acids Res. 20: 2361-2366.

Dignam, J.D., R.M. Lebovitz, and R.G. Roeder. 1983. Accurate transcription initiation by RNA polymerase II in a soluble extract from isolated mammalian nuclei. Nucleic Acids Res. 11: 1475-1489.

Domenjoud, L., H. Gallinaro, L. Kister, S. Meyer, and M. Jacob. 1991. Identification of a specific exon sequence that is a major determinant in the selection between a natural and a cryptic 5' splice site. Mol. Cell Biol. 11: 4581-4590.

Fu, X.-D. and T. Maniatis. 1992. The 35-kDa mammalian splicing factor SC35 mediates specific interactions between U1 and U2 small nuclear ribonucleoprotein particles at the $3^{\prime}$ splice site. Proc. Natl. Acad. Sci. 89: 1725-1729.

Fu, X.-D., A. Mayeda, T. Maniatis, and A.R. Krainer. 1992. General splicing factors SF2 and SC35 have equivalent activities in vitro, and both affect alternative $5^{\prime}$ and $3^{\prime}$ splice site selection. Proc. Natl. Acad. Sci. 89: 11224-11228.

Furdon, P.J. and R. Kole. 1986. Inhibition of splicing but not cleavage at the $5^{\prime}$ splice site by truncating human betaglobin pre-mRNA. Proc. Natl. Acad. Sci. 83: 927-931.

Gallego, M.E., L. Balvay, and E. Brody. 1992. cis-acting sequences involved on exon selection in the chicken $\beta$-tropomyosin gene. Mol. Cell. Biol. 12: 5415-5425.

Garcia-Blanco, M.A., S.F. Jamison, and P.A. Sharp. 1989. Identification and purification of a 62,000 -dalton protein that binds specifically to the polypyrimidine tract of introns. Genes \& Dev. 3: 1874-1886.

Grabowski, P.J., F.U. Nasim, H.C. Kuo, and R. Burch. 1991. Combinatorial splicing of exon pairs by two-site binding of Ul small nuclear ribonucleoprotein particle. Mol. Cell. Biol. 11: 5919-5928.

Graham, I.R., M. Hamshere, and I.C. Eperon. 1992. Alternative splicing of a human $\alpha$-tropomyosin muscle-specific exon: Identification of determining sequences. Mol. Cell. Biol. 12: 3872-3882.

Green, M.R. 1991. Biochemical mechanisms of constitutive and regulated pre-mRNA splicing. Annu. Rev. Cell. Biol. 7: 559599.

Guthrie, C. 1991. Messenger RNA splicing in yeast: Clues to why the spliceosome is a ribonucleoprotein. Science 253: 157-163.

Hampson, R.K., L. La Follette, and F.M. Rottman. 1989. Alternative processing of bovine growth hormone mRNA is influenced by downstream exon sequences. Mol. Cell. Biol. 9: 1604-1610.

Hedley, M.L. and T. Maniatis. 1991. Sex-specific splicing and polyadenylation of dsx pre-mRNA requires a sequence that binds specifically to tra-2 protein in vitro. Cell 65: $579-586$.

Hinterberger, M., I. Pettersson, and J.A. Steitz. 1983. Isolation of small nuclear ribonucleoproteins containing U1, U2, U4, U5 and U6 RNAs. J. Biol. Chem. 258: 2604-2613.

Hoffman, B.E. and P.I. Grabowski. 1992. U1 snRNP targets an essential splicing factor, U2AF65, to the $3^{\prime}$ splice site by a network of interactions spanning the exon. Genes \& Dev. 6: $2554-2568$.

Hoshijima, K., K. Inoue, I. Higuchi, H. Sakamoto, and Y. Shimura. 1991. Control of doublesex alternative splicing by transformer and transformer-2 in Drosophila. Science 252:
833-836.

Krainer, A.R. and T. Maniatis. 1985. Multiple factors including the small nuclear ribonucleoproteins $U 1$ and $U 2$ are necessary for pre-mRNA splicing in vitro. Cell 42: 725-736.

Krainer, A.R., G.C. Conway, and D. Kozak. 1990a. The essential pre-mRNA splicing factor SF2 influences 5 ' splice site selection by activating proximal sites. Cell 62: $35-42$.

. 1990b. Purification and characterization of pre-mRNA splicing factor SF2 from HeLa cells. Genes \& Dev. 4: 11581171.

Kuo, H.C., F.H. Nasim, and P.J. Grabowski. 1991. Control of alternative splicing by the differential binding of Ul small nuclear ribonucleoprotein particle. Science 251: 1045-1050.

Libri, D., M. Goux-Pelletan, E. Brody, and M.Y. Fiszman. 1990. Exon as well as intron sequences are cis-regulating elements for the mutually exclusive alternative splicing of the beta tropomyosin gene. Mol. Cell. Biol. 10: 5036-5046.

Madhani, H.D. and C. Guthrie. 1992. A novel base-pairing interaction between U2 and U6 snRNAs suggests a mechanism for the catalytic activation of the spliceosome. Cell 71: 803-817.

Maniatis, T. 1991. Mechanisms of alternative pre-mRNA splicing. Science 251: 33-34.

Mardon, H.J., G. Sebastio, and F.E. Baralle. 1987. A role for exon sequences in alternative splicing of the human fibronectin gene. Nucleic Acids Res. 15: 7725-7733.

Mayeda, A. and A.R. Krainer. 1992. Regulation of alternative pre-mRNA splicing by hnRNP A1 and splicing factor SF2. Cell 68: 365-375.

Mayeda, A., A.M. Zahler, A.R. Krainer, and M.B. Roth. 1992. Two members of a conserved family of nuclear phosphoproteins are involved in pre-mRNA splicing. Proc. Natl. Acad. Sci. 89: 1301-1304.

Mayeda, A., D.M. Helfman, and A.R. Krainer. 1993. Modulation of exon skipping and inclusion by heterogeneous nuclear ribonucleoprotein A1 and pre-mRNA splicing factor SF2/ ASF. Mol. Cell. Biol. 13: 2993-3001.

Nasim, F.H., P.A. Spears, H.M. Hoffmann, H.C. Kuo, and P.J. Grabowski. 1990. A sequential splicing mechanism promotes selection of an optimal exon by repositioning a downstream 5 ' splice site in preprotachykinin pre-mRNA. Genes \& Dev. 4: 1172-1184.

Nemeroff, M.E., U. Utans, A. Kramer, and R.M. Krug. 1992. Identification of cis-acting intron and exon regions in influenza virus NS1 mRNA that inhibit splicing and cause the formation of aberrantly sedimenting presplicing complexes. Mol. Cell. Biol. 12: 962-970.

Newman, A. and C. Norman. 1991. Mutations in yeast U5 snRNA alter the specificity of $5^{\prime}$ splice-site cleavage. Cell 65: 115-123.

1992. U5 snRNA interacts with exon sequences at $5^{\prime}$ and 3' splice sites. Cell 68: 743-754.

Parent, A., S. Zeitlin, and A. Efstratiadis. 1987. Minimal exon sequence requirements for efficient in vitro splicing of mono-intronic nuclear pre-mRNA. J. Biol. Chem. 262: 11284-11291.

Reed, R. and T. Maniatis. 1986. A role for exon sequences and splice-site proximity in splice site selection. Cell 46: 681690.

Reich, C.I., R.W. VanHoy, G.L. Porter, and J.A. Wise. 1992. Mutations at the $3^{\prime}$ splice site can be suppressed by compensatory base changes in Ul snRNA in fission yeast. Cell 69: 1159-1169.

Robberson, B.L., G.J. Cote, and S.M. Berget. 1990. Exon definition may facilitate splice site selection in RNAs with multiple exons. Mol. Cell. Biol. 10: 84-94. 
Ruskin, B. and M.R. Green. 1985. Role of the $3^{\prime}$ splice site consensus sequence in mammalian pre-mRNA splicing. $\mathrm{Na}$ ture 317: 732-734.

Ruskin, B., P.D. Zamore, and M.R. Green. 1988. A factor, U2AF, is required for U2 snRNP binding and splicing complex assembly. Cell 52: 207-219.

Sawa, H. and J. Abelson. 1992. Evidence for a base-pairing interaction between U6 small nuclear RNA and the $5^{\prime}$ splice site during the splicing reaction in yeast. Proc. Natl. Acad. Sci. 89: 11269-11273.

Siebel, C.W., L.D. Fresco, and D.C. Rio. 1992. The mechanism of somatic inhibition of Drosophila P-element pre-mRNA splicing: Multiprotein complexes at an exon pseudo-5' splice site control Ul snRNP binding. Genes \& Dev. 6: 1386-1401.

Smith, C.W., J.G. Patton, and B. Nadal-Ginard. 1989. Alternative splicing in the control of gene expression. Annu. Rev. Genet. 23: 527-577.

Streuli, M. and H. Saito. 1989. Regulation of tissue-specific alternative splicing: Exon-specific cis-elements govern the splicing of leukocyte common antigen pre-mRNA. EMBO $J$. 8: 787-796.

Swanson, M.S. and G. Dreyfuss. 1988. RNA binding specificity of hnRNP proteins: A subset bind to the 3 ' end of introns. EMBO I. 7: 3519-3529.

Tacke, R. and C. Goridis. 1991. Alternative splicing in the neural cell adhesion molecule pre-mRNA: Regulation of exon 18 skipping depends on the 5 '-splice site. Genes \& Dev. 5: 1416-1429.

Talerico, M. and S.M. Berget. 1990. Effect of $5^{\prime}$ splice site mutations on splicing of the preceding intron. Mol. Cell. Biol. 10: 6299-6305.

Tian, M. and T. Maniatis. 1992. Positive control of pre-mRNA splicing in vitro. Science 256: 237-240.

- 1993. A splicing enhancer complex controls alternative splicing of doublesex pre-mRNA. Cell 74: 105-114.

Wassarman, D.A. and J.A. Steitz. 1992. Interactions of small nuclear RNAs with precursor messenger RNA during in vitro splicing. Science 257: 1918-1925.

Watakabe, A., K. Tanaka, and Y. Shimura. 1993. The role of exon sequences in splice site selection. Genes \& Dev. 7: 407-418.

Xu, R., J. Teng, and T.A. Cooper. 1993. The cardiac troponin T alternative exon contains a novel purine-rich positive splicing element. Mol. Cell. Biol. 13: 3660-3674.

Zahler, A.M., W.S. Lane, J.A. Stolk, and M.B. Roth. 1992. SR proteins: A conserved family of pre-mRNA splicing factors. Genes \& Dev. 6: 837-847.

Zahler, A.M., K.M. Neugebauer, W.S. Lane, and M.B. Roth. 1993a. Distinct functions of SR proteins in alternative premRNA splicing. Science 260: 219-222.

Zahler, A.M., K.M. Neugebauer, J.A. Stolk, and M.B. Roth. $1993 \mathrm{~b}$. Human SR proteins and isolation of a cDNA encoding SRp75. Mol. Cell. Biol. 13: 4023-4028.

Zamore, P.D. and M.R. Green. 1989. Identification, purification, and biochemical characterization of $\mathrm{U} 2$ small nuclear ribonucleoprotein auxiliary factor. Proc. Natl. Acad. Sci. 86: 9243-9247. 


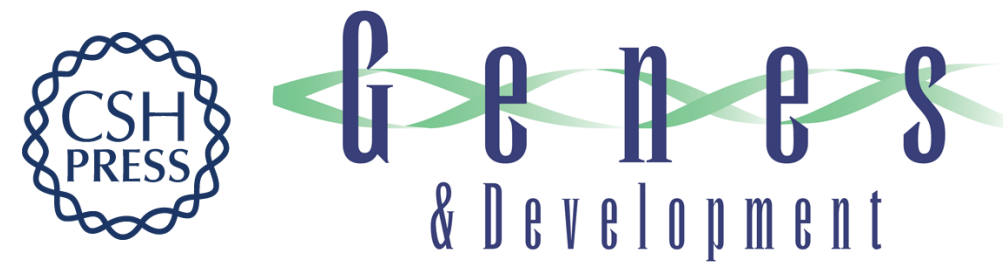

\section{A splicing enhancer in the human fibronectin alternate ED1 exon interacts with SR proteins and stimulates U2 snRNP binding.}

A Lavigueur, H La Branche, A R Kornblihtt, et al.

Genes Dev. 1993, 7:

Access the most recent version at doi:10.1101/gad.7.12a.2405

References

This article cites 62 articles, 40 of which can be accessed free at:

http://genesdev.cshlp.org/content/7/12a/2405.full.html\#ref-list-1

License

Email Alerting

Receive free email alerts when new articles cite this article - sign up in the box at the top

Service right corner of the article or click here.

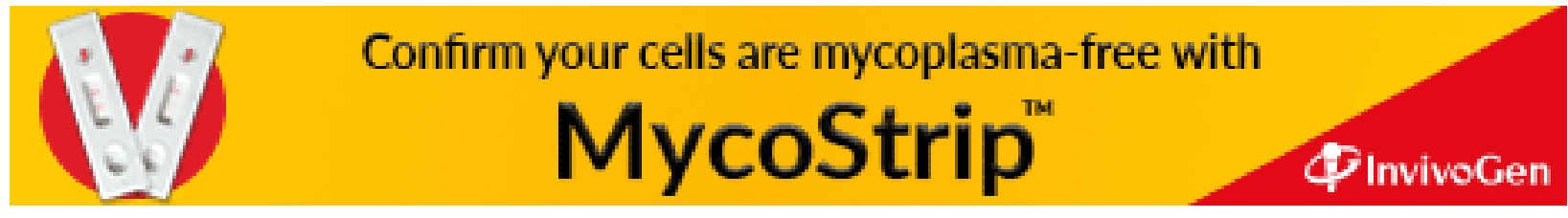

